\title{
Líderes para el próximo siglo
}

\section{Carrasco, Juan*}

\section{Resumen}

Conocer las nuevas fuentes de poder de un líder así como las habilidades requeridas para afrontar los cambios tecnológicos, organizacionales y humanos que inevitablemente traerá consigo el siglo XXI, es de suma importancia para aquellas organizaciones que deseen afrontar exitosamente el nuevo milenio. El objetivo de este artículo es presentar una definición contemporánea de liderazgo, asi como las nuevas fuentes de poder y habilidades requeridas por los líderes para enfrentar los retos del siglo $X X \mid$ según Luigi Valdes en su libro "Conocimiento es futuro". Del análisis bibliográfico realizado se deduce que algunas de las nuevas fuentes de poder del líder para el siglo XXI son: estructuración y maximización del conocimiento; uso eficiente de la información; conexiones sociales y comunicaciones. Adicionalmente, las nuevas habilidades para estos líderes son: habilidad para transferir la pertenencia de la visión, habilidad de formar seguidores, la habilidad de negociación, la habilidad para generar cambios y la habilidad de facultar.

Palabras clave: Liderazgo, habilidades del líder, fuentes de poder del líder.

\section{Recibido: 98-06-15 . Aceptado: 99-03-15}

- Licenciado en Matemáticas Summa Cum Laude. Maestría en Matemáticas Aplicadas en LUZ. Estudiante del Doctorado en Ciencias Gerenciales de la Universidad Rafael Belloso Chacín (URBE). Email: jcarrasco@ cantv.net 


\title{
Leaders for the Next Century
}

\begin{abstract}
It is extremely important for organizations that wish to face the new millennium successfully to know what a leader's new sources of power will be as well as what abilities he will require to meet the technological, organizational and human changes that the twentyfirst century will inevitably bring. The objective of this article is to present a contemporary definition of leadership, as well as of the new sources of power and the abilities required by leaders to face the challenges of the twenty-first century, according to Luigi Valdes in his book "Knowledge is future". From the bibliographic analysis carried out, some of the new sources of power for the twenty-first century leader are deduced to be: structuring and maximization of knowledge; efficient use of information; social connections and communications. In addition, new abilities for these leaders are: the ability to transfer the ownership of a vision, the ability to create followers, the ability to negotiate, the ability to generate changes and the ability to empower.
\end{abstract}

Key words: Leadership, abilities of a leader, sources of power for a leader.

\section{Introducción}

Hablar de liderazgo es referirnos a un concepto polémico, cuya práctica ha sido objeto de muchas investigaciones sociales, que abarcan desde el perfil de liderazgo desarrollado y adoptado por algunos líderes a lo largo de la historia de la humanidad, hasta la identificación de los elementos o circunstancias que generan y mantienen a los líderes al frente de los grupos sociales. En este artículo se pretende conceptualizar el término liderazgo, analizar las habilidades y fuentes de poder de los líderes para el siglo XXI y emitir una reflexión sobre el particular.

En las organizaciones del futuro, el éxito de los líderes dependerá mucho más de una estructura organizacional inteligente y procesos robustos, que de su carisma y personalidad, ya que estas organizaciones funcionarán en un diseño organizacional del tipo "reacción en cadena". Es decir, un diseño que estimula y reta el desarrollo mental de cada uno de los miembros de la organización, provoca la continua generación de conocimientos y asegura que cada nueva experiencia sea incorporada y compartida en toda la organización (Valdes, 1995: 389).

La toma de decisiones descentralizada, la delegación del poder sin evitar la responsabilidad y la información y conocimientos compartidos, obligará al líder a desarrollar nuevas habilidades que le facilitarán la creación de seguidores más inteligentes y capaces de generar y administrar cambios.

Aunque el líder basará gran parte de su éxito en una estructura inteligente, 
sus habilidades y capacidades serán de terminantes para guiar y potenciar el aprendizaje y ayudar a sus organizaciones a encontrar el rumbo, cuando estas pierdan la brújula.

Sin importar cuanto evolucionen las instituciones, el éxito o el fracaso de las organizaciones dependerá de la calidad de liderazgo ejercido por los hombres que enfrenten el reto cotidiano de desarrollar habilidades para conducir el cambio y a la vez influir en su rumbo, dirección y amplitud.

\section{La esencia del liderazgo}

En la sociedad moderna, que puede describirse como deseosa de alguien que la conduzca, el líder de hoy, está obligado a ser un constante agente de cambio. Por su parte, las organizaciones demandan de una nueva generación de líderes, capaces de retar los procesos, inspirar una visión compartida, levantar los ánimos y canalizar positivamente la inconformidad, así como de capacitar a otros para la acción.

El líder enfrenta el reto cotidiano de desarrollar habilidades para conducir el cambio y a la vez influir en su rumbo, dirección y amplitud. Algunos lo han logrado, otros, simplemente lo han dejado pasar, perdiendo su condición de líderes.

Los líderes son pioneros por naturaleza, se atreven a salir de lo convencional y buscan nuevas formas de hacer las cosas. Esta práctica la realizan mediante dos compromisos: la búsqueda de oportunidades y la toma de decisiones. No obstante, antes de poder ejercer un liderazgo efectivo, es preciso que el líder genere la habilidad para dirigir su propio avance. El verdadero líder es quien comienza a educarse a sí mismo y perfeccionarse en la práctica de las virtudes humanas. Debiendo predicar con su ejemplo estará marcando la pauta para que otros a su vez busquen desarrollarse $y$ desempeñarse de una manera integral. Como aspecto primordial, el líder de cualquier grupo social, debe estar comprometido con el reto de incrementar el valor o la importancia de su propia organización.

Liderazgo ha sido definido en términos de rasgos individuales, patrones, relaciones, percepción de los seguidores, influencia sobre los seguidores, influencia sobre las tareas e influencia sobre la cultura organizacional (Yukl, 1989: 52). Por ello, existe un sin número de definiciones de liderazgo, en las que hay un denominador común: influir en la conducta de los demás, como individuos o grupo de personas.

En general, liderazgo es aquel proceso mediante el cual sistemáticamente un individuo ejerce más influencia que otros en el desarrollo de las funciones del grupo. No se trata, pues, de influencias ocasionales o esporádicas, ni de influencias ligadas al ejercicio de una tarea de grupo concreta. Se trata de una influencia permanente, que tiene un referente colectivo, toda vez que se dirige sobre un número relativamente amplio de personas y durante un tiempo considerable.

El liderazgo, al ser un fenómeno dinámico, requiere que tanto el líder como sus seguidores se adapten continuamente a las nuevas reglas del juego (Valdes, 1995: 395) y para ello requiere nuevas habilidades y nuevas fuentes de poder. 


\section{Las nuevas habilidades del líder}

Las organizaciones actuales requieren de una nueva conceptualización del liderazgo. La esencia no ha cambiado, ni cambiará en el futuro, sólo que los lideres deberán desarrollar nuevas habilidades y capacidades que permitan influir sobre sus seguidores y ayudar a sus organizaciones a enfrentar con mayor éxito el futuro. Dentro de las habilidades que debe desarrollar las organizaciones inteligentes destacan:

\subsection{Habilidad para transferir la pertenencia de la visión}

Para elegir un rumbo, el lider debe primero haber desarrollado la imagen mental de un futuro posible y deseable para la organización. Esta imagen, que se puede llamar visión puede ser tan vaga como un sueño o tan precisa como una misión. Una imagen de una condición que sea más deseable y, lo que es muy importante, mejor que la situación existente. El punto crítico es que una visión debe articular una proyección de un futuro realista, creible y atractivo para la organización y para las personas que laboran en ella. Para que la visión sea efectiva, necesita ser entendida, creída y apoyada por el grupo, ya que si no es compartida por los seguidores, no pasará de ser una buena intención en la cabeza del líder.

El liderazgo de alto nivel ocurre cuando los líderes generan aceptación y compromiso del propósito y misión del grupo (Bass, 1990: 21). Para lograr el apoyo de los seguidores, el líder debe saber compartir la visión y hacer que sus seguidores la adopten como propia. Los If- deres deben ser verdaderos expertos en transferir la pertenencia de la visión a todo el grupo. Los líderes deben saber "vender" en que consiste, cuáles son los beneficios esperados, las dificultades para conseguirlos, el cómo, cuándo, dónde y sobre todo el por qué; deben conocer el esfuerzo y la energía que se requiere para lograrla; deben saber expresarla de una manera gráfica, sencilla, tangible y dramatizada (Valdes, 1995: 402).

La visión, a la vez que simplifica el liderazgo, lo fortalece. Por tanto, la visión es indispensable para los líderes que quieran asegurar un desempeño y rentabilidad óptimos para el siglo XXI (McFarland, 1996: 114).

\subsection{La habilidad de formar seguidores}

Cuando se le preguntó a alguien lo que se necesitaba para ser un gran líder, respondió: "Grandes seguidores!", (Robbins, 1997: 443). Todo lider es un guía y un conductor de personas y grupos humanos. Los seguidores se dejarán guiar cuando un lider les elimine miedos, inseguridades y confusiones de percepción. A lo largo de la historia, se ha demostrado que el camino más efectivo que tiene un líder para guiar a sus seguidores es por medio del ejemplo. El líder debe desarrollar la habilidad de ejecutar acciones simbólicas que reafirmen su compromiso constante con sus seguidores.

\subsection{La habilidad de negociación}

El mundo es cada vez más democrático. Los ciudadanos en todo el mundo quieren que su voz sea escuchada; los clientes, mediante su elección hacen oir su voz; los nuevos empleados quieren 
participar activamente en las decisiones de la empresa y ser parte de las soluciones. Además, en situaciones consideradas inusuales, las empresas tienen que pactar e inclusive formar alianzas con sus propios competidores. Por esto los líderes deben desarrollar su capacidad de negociar. Un líder debe saber que una buena negociación se debe establecer en condiciones de ganar-ganar, la cual consiste en tratar de que las dos partes resulten con un beneficio. Sólo así se pueden realizar negociaciones duraderas y permanentes.

\subsection{Habilidad para generar cambios}

Muchas de las ideas y de las oportunidades que surgen en el camino, tienen que ver con un cambio de paradigma. Uno de los grandes secretos para los líderes en el presente y futuro es desafiar las reglas establecidas. Vaciar completamente la mente y hacer un lugar para las nuevas ideas será el primer trabajo de un líder que quiera seguir siéndolo. El siglo $X X I$ será el siglo de las ideas y el líder tendrá que ser un generador de ellas y un eterno estructurador de las ideas de los demás. El papel de los líderes será el deseo de trascender la norma, de cuestionar el estado de las cosas, de salirse del patrón (Taffinder, 1998: 82).

\subsection{La habilidad para facultar (empowerment)}

Los lideres deben dar a los subordinados el poder de decidir y actuar como una forma de incrementar su propio poder (Kirkpatrick, 1991: 48). El papel del lider que faculta es mostrar confianza y visión de las cosas, eliminar barreras que bloqueen el desempeño, ofrecer estímu- lo, motivar y capacitar a sus seguidores (Robbins, 1997: 443).

\section{Las nuevas fuentes de poder de un líder}

En una estructura organizacional piramidal y jerárquica cuando una persona tiene una posición jerárquica más alta, automáticamente tiene más poder. Esta situación pudiera traer consecuencias negativas a más de una institución. Aparte de atrofiar otras habilidades necesarias para un líder, como la habilidad de facultar, casi siempre se desarrolla una competencia por ganar-perder entre el jefe y sus subalternos. Se crea una rigidez dentro de las organizaciones, que va desde buscar permisos por cada acción emprendida, hasta desgastantes labores de convencimiento de los subalternos hacia el jefe. La jerarquía inclusive puede limitar la especialización de los subalternos.

Sin embargo, si la transformación de las empresas habla de la evolución hacia estructuras más avanzadas, democráticas y dinámicas, las fuentes de poder evolucionan con ella (Valdes, 1995: 396). Las nuevas fuentes de poder de un líder son:

\subsection{Estructuración y maximización del conocimiento}

No se trata de que el líder se convierta en el especialista de una determinada materia sino de saber utilizar las fuentes de conocimiento disponibles. Un lider que quiera aprovechar el conocimiento como fuente de poder debe desarroilar las siguientes habilidades: saber identificar la información que necesita; 
encontrar los medios electrónicos para acceder a esta información y hacerla de dominio público en su organización; desarrollar la capacidad de relacionar nuevos conocimientos con los anteriores para producir conocimientos superiores; y estandarizar los conocimientos de tal manera que se estructuren y transiten libremente por toda la organización.

\subsection{Uso eficiente de la información}

La información es el insumo que ayuda a acelerar el paso o corregir el rumbo, según las tendencias del entorno. No hay pecado más grande en un líder que buscar alcanzar metas u objetivos que ya no son realizables. Sólo con información completa, oportuna y veraz podrá corregir el rumbo a tiempo. Con buenos sistemas de información podrá transitar de ser un planeador estratégico a un administrador estratégico capaz de virar el rumbo cada vez que las oportunidades y condiciones del entorno lo requieran (Naisbitt, 1991: 65-66).

El líder debe saber que existen seis características entrelazadas de la información que pueden cambiar radicalmente la relación con sus seguidores. Estas características son: capacidad de expansión, capacidad de compresión, transportable, compartible, difusa y capaz de reemplazar tierra, labor y capital (Bass, 1981: 881).

\subsection{Las conexiones sociales y las comunicaciones}

Un lider debe entender que uno de sus papeles principales es el de enlace dentro y fuera de la organización. Los verdaderos líderes deben tejer una telaraña de relaciones, amistades y compromisos con todos los elementos que puedan llegar a influir en una decisión o le aporten puntos de vistas interesantes (Valdes, 1995: 398).

\section{Reflexión final}

La vida es demasiado compleja, la información está demasiado especializa$\mathrm{da}$, la sociedad tiene muchas facetas, tenemos que entender que se necesita un estilo distinto de liderazgo.

El reto de los líderes hoy en día es poder guiar, dirigir e interactuar con gente más preparada, más informada y mejor educada. Se necesitan líderes que promuevan el arraigo, el sentido de pertenencia y la colaboración libre y responsable hacia los resultados. El éxito de un lider será proporcional a su capacidad de administrar los talentos de su gente. La sociedad del conocimiento y de la información, y el capital intelectual como las formas de conducir a las empresas requerirán de un líder que pueda desarrollar un ambiente de confianza y experimentación donde la gente pueda probar, aprender y mejorar y volver a probar. La capacidad de un lider para dirigir, orientar y optimizar el ingenio del hombre será uno de sus factores clave de éxito.

A las puertas del siglo XXI el mundo reclama a un tipo singular de líderes que tengan la capacidad de interrelacionar el sentido tecnológico con un fuerte sentido humano. El mundo busca líderes: que muestren su amor por encima de su egoismo; que posean valores sólidos, con un amplio sentido de justicia social y con una verdadera conciencia universal; líderes que actúen localmente, pero que piensen globalmente, líderes que puedan 
crear el "si", después de tantos "no" (Valdes, 1995: 408-410).

\section{Bibliografía citada}

Bass, Bernard (1981). Bass \& Stogdill's handbook of leadership: theory, research, and managerial applications. The Free Press. Estados Unidos.

Bass, Bernard (1990). From transactional to transformational leadership: learning to share the vision, en Organizational Dynamics. Estados Unidos.

Kirkpatrick, S. y Locke, E. (1991). Leadership: do traits matter?, en Academy of Management Executive. Vol 5. № 2. Estados Unidos.
McFarland, Lynne Joy y otros (1996). Liderazgo para el siglo XXI. McGraw-Hill. Colombia.

Naisbitt, J. (1991). Mega Tendencias 2000. Editorial Norma. Colombia.

Robbins, Stephen P. (1997). Comportamiento Organizacional. Prenticer Hill. México.

Taffinder, Paul (1998). Los nuevos líderes. Panorama. México.

Valdes, Luigi (1995). Conocimiento es futuro: hacia la sexta generación de calidad. Concamin. México.

Yukl, Gary (1989). Managerial Leadership: A review of theory and research, en Journal of Management. Vol 15. № 2. Estados Unidos. 